\title{
LA LEGITIMACIÓN DEL SUPUESTO PROGENITOR PARA EJERCITAR LA ACCIÓN DE RECLAMACIÓN DE LA FILIACIÓN NO MATRIMONIAL SIN POSESIÓN DE ESTADO
}

JAVIER MARTÍNEZ CALVO ${ }^{1}$

\section{Resumen}

El objeto de este artículo es llevar a cabo un estudio acerca de la evolución de la legitimación activa del progenitor para interponer la acción de reclamación de la paternidad cuando no existe posesión de estado. Para ello se analizará la jurisprudencia del Tribunal Supremo y la del Tribunal Constitucional, así como el impacto de dicha jurisprudencia en la modificación legislativa llevada a cabo a través de la Ley 26/2015.

Palabras clave

Filiación, paternidad, posesión de estado, legitimación activa, jurisprudencia.

\section{THE LEGITIMATION OF THE ALLEGED PROGENITOR TO FILE THE PATERNITY CLAIM WITHOUT POSSESSION OF STATUS}

\section{Abstract}

The subject of this article is to carry out a study of evolution of progenitor's active legitimation to file the paternity claim when there isn't possession of status. For it, we will analyse the Tribunal Supremo's and Tribunal Constitucional's jurisprudence, as well as the impact of such jurisprudence on the change in the legislation implemented through the Law 26/2015.

Keywords

Filiation, paternity, possession of status, active legitimation, jurisprudence.

\footnotetext{
1 Doctor en Derecho por la Universidad de Zaragoza. Ha trabajado como abogado ejerciente y posteriormente ha estado vinculado a la Universidad de Zaragoza como personal docente e investigador. También ha cursado el Máster Universitario en Especialización e Investigación en Derecho y el Máster Universitario en Profesorado de Educación Secundaria Obligatoria. Su labor investigadora se desarrolla en el seno del Grupo Consolidado de Investigación Ius Familiae y del Proyecto de Investigación "Prospectiva sobre el ejercicio de la capacidad: la interrelación entre las reformas legales en materia de discapacidad y menores". Sus líneas de investigación principales son: derecho de la persona, filiación, derecho de familia, mediación familiar y protección de menores y discapacitados. En el marco de las mismas, ha llevado a cabo diversas investigaciones que han dado como fruto varias publicaciones científicas. Dirección de correo: javiermc@unizar.es.
} 


\section{I) Introducción}

La evolución de la institución de la filiación en los últimos tiempos ha estado marcada por la desvinculación entre matrimonio y procreación, es decir, el matrimonio cada vez tiene menos que ver con la filiación, así como la filiación con el matrimonio ${ }^{2}$. Como consecuencia de ello no sólo se ha producido una equiparación absoluta en cuanto a derechos de los hijos matrimoniales y no matrimoniales, sino que como veremos en las siguientes páginas, se tiende cada vez más a una equiparación de derechos de los progenitores a la hora de determinar la filiación, ya sea ésta matrimonial o extramatrimonial ${ }^{3}$. Aunque como se pondrá de manifiesto, al igual que ocurre tantas otras veces, la jurisprudencia ha ido por delante de la ley, y podemos afirmar que han sido nuestros tribunales los que más han contribuido a esta equiparación.

El objeto de este estudio es atender a la evolución de la legitimación activa del supuesto progenitor para interponer la acción de reclamación de la paternidad cuando no existe posesión de estado ${ }^{4}$. Esta cuestión está prevista en el artículo 133 de nuestro Código Civil, que tradicionalmente reconocía legitimación activa para reclamar la filiación no

\footnotetext{
${ }^{2}$ MARTíNEZ DE AGUIRRE ALDAZ señala textualmente que "la historia de la evolución del matrimonio en los últimos decenios es la historia de la desvinculación entre matrimonio y procreación" —MARTÍNEZ DE Aguirre Aldaz, Carlos, "La filiación, entre biología y derecho", Prudentia iuris, № 76, 2013-. Al respecto señala como principales causas de este proceso a la desaparición del impedimento de impotencia en el matrimonio civil y a la admisión del matrimonio civil entre personas del mismo texto.

${ }^{3}$ GARCÍA ViCENTE considera que el Código Civil vigente conserva residualmente un cierto repudio hacia la familia no matrimonial, de tal modo que la protección de la familia matrimonial se sostiene en la relativa desprotección de la no matrimonial - GARCÍA VICENTE, José Ramón. "Los principios del Derecho de las acciones de filiación", Aranzadi Civil: revista quincenal, № 1, 2004-.

${ }^{4}$ La jurisprudencia dice que "la posesión de estado consiste en el concepto público en que es tenido un hijo con relación a su padre natural, cuando este concepto se forma por actos directos del mismo padre o de su familia, demostrativos de un verdadero reconocimiento perfectamente voluntario, libre y espontáneo" STS de 10 de marzo de 1988: RJ 1988, 1815-.
} 
matrimonial únicamente en favor de los hijos y herederos de éstos, excluyendo por tanto al progenitor con el que no existe posesión de estado.

No obstante, la jurisprudencia del Tribunal Supremo comenzó a interpretar extensivamente la legitimación activa en esta materia y, el Tribunal Constitucional, terminó declarando la inconstitucionalidad del punto primero del art. 133 Cc., en la medida de ampliar la legitimación activa para ejercitar la acción de reclamación de la filiación no matrimonial al progenitor cuando falte la respectiva posesión de estado ${ }^{5}$.

Finalmente, con la entrada en vigor de Ley 26/2015, de 28 de julio, el artículo 133 del Código Civil fue objeto de reforma y pasó a recoger expresamente la legitimación activa del progenitor para ejercitar la acción de reclamación de la filiación no matrimonial cuando falte la respectiva posesión de estado.

Comenzaré el estudio con una breve descripción de la normativa legal que incide en esta materia, y que iré trayendo a colación a la hora de analizar la jurisprudencia de nuestros tribunales.

Posteriormente, me referiré por separado a la jurisprudencia del Tribunal Supremo y a la del Tribunal Constitucional, que, como he adelantado, declaró la inconstitucionalidad de la redacción anterior del artículo 133 Cc. También abordaré el impacto de dicha jurisprudencia en la modificación legislativa posterior.

\section{II) Marco legal}

La Constitución Española recoge varios principios que inciden en la regulación legal de la filiación: la igualdad de los hijos ante la ley, con independencia de su filiación

\footnotetext{
${ }^{5}$ En palabras de GARCíA VICENTE, dentro de su artículo dedicado a los principios del derecho en las acciones de filiación, "la abstracción y el recurso a normas de tenor tan abierto a la interpretación, permite obtener variadas soluciones e interpretaciones, ajustadas a las normas constitucionales, aunque se muestren simultáneamente inseguras" —GARCÍA VICENTE, José Ramón. "Los principios del Derecho de las acciones de filiación", Aranzadi Civil: revista quincenal, № 1, 2004-.
} 
—art. 14 y $39.2 \mathrm{CE}^{6}{ }^{6}$, principio previsto también en el artículo 108 del Código Civil ${ }^{7}$; el derecho a la tutela judicial efectiva —art. 24.1 CE— ${ }^{8}$; la libre investigación de la paternidad, que habrá de ser facilitada por la ley —art. 39.2 CE—9 y que, como señala MARTíneZ DE AGUIRRE ALDAZ, sirve para fundamentar constitucionalmente el principio de veracidad biológica, conforme al que es padre jurídicamente quien lo es biológicamente ${ }^{10}$; el deber de los padres de prestar asistencia de todo orden a los hijos habidos dentro o fuera del matrimonio - art. 39.3 CE— ${ }^{11}$; y la protección integral de los hijos —art. $39.2 \mathrm{CE}{ }^{12}$.

En cuanto al Código Civil, se refiere a la filiación en el Título V de su Libro Primero — artículos 108 a 141—. Las acciones de filiación se recogen en los siguientes artículos: 131 - para la reclamación de la filiación matrimonial o no matrimonial cuando existe posesión de estado—— ${ }^{13} ; 132$ — para la reclamación de la filiación matrimonial

\footnotetext{
${ }^{6} \mathrm{El}$ artículo $14 \mathrm{CE}$ dispone que «Los españoles son iguales ante la ley, sin que pueda prevalecer discriminación alguna por razón de nacimiento, raza, sexo, religión, opinión o cualquier otra condición o circunstancia personal o social»; mientras que el artículo 39.2 CE señala que «Los poderes públicos aseguran, asimismo, la protección integral de los hijos, iguales éstos ante la ley con independencia de su filiación, y de las madres, cualquiera que sea su estado civil(...)».
}

${ }^{7}$ El artículo 108 Cc. señala que «La filiación matrimonial y la no matrimonial, así como la adoptiva, surten los mismos efectos, conforme a las disposiciones de este Código».

${ }^{8}$ El artículo 14 CE prevé que «Todas las personas tienen derecho a obtener la tutela efectiva de los jueces y tribunales en el ejercicio de sus derechos e intereses legítimos, sin que, en ningún caso, pueda producirse indefensión».

${ }^{9} \mathrm{El}$ artículo 39.2 CE dispone que «(...) La ley posibilitará la investigación de la paternidad».

${ }^{10}$ Vid. Martínez de Aguirre Aldaz, Carlos, "La filiación", en: Curso de Derecho Civil (IV): Derecho de familia - coord. MARTínEZ DE AGUIRRE ALDAZ, Carlos-, Edisofer, 2016, 5ª ed., p. 325.

${ }^{11}$ El artículo 39.3 CE señala que «Los padres deben prestar asistencia de todo orden a los hijos habidos dentro o fuera del matrimonio, durante su minoría de edad y en los demás casos en que legalmente proceda».

${ }^{12} \mathrm{El}$ artículo 39.2 CE prevé que «Los poderes públicos aseguran, asimismo, la protección integral de los hijos».

${ }^{13}$ El artículo $131 \mathrm{Cc}$. dispone que «Cualquier persona con interés legítimo tiene acción para que se declare la filiación manifestada por la constante posesión de estado. Se exceptúa el supuesto en que la filiación que se reclame contradiga otra legalmente determinada». 
cuando no existe posesión de estado — ${ }^{14}$; 133 — para la reclamación de la filiación no matrimonial cuando no existe posesión de estado_ ${ }^{15}$; 136, 137 y 139 —para la impugnación de la filiación matrimonial—16; $; 140.1$ — para la impugnación de la filiación no matrimonial cuando existe posesión de estado— — ${ }^{17}$; y 140.2 —para la impugnación de la filiación no matrimonial cuando no existe posesión de estado—— ${ }^{18}$.

\footnotetext{
${ }^{14} \mathrm{El}$ artículo $132 \mathrm{Cc}$. prevé que «A falta de la correspondiente posesión de estado, la acción de reclamación de la filiación matrimonial, que es imprescriptible, corresponde al padre, a la madre o al hijo. Si el hijo falleciere antes de transcurrir cuatro años desde que alcanzase plena capacidad, o durante el año siguiente al descubrimiento de las pruebas en que se haya de fundar la demanda, su acción corresponde a sus herederos por el tiempo que faltare para completar dichos plazos».
}

${ }^{15}$ El artículo 133 Cc. señala que «1. La acción de reclamación de filiación no matrimonial, cuando falte la respectiva posesión de estado, corresponderá al hijo durante toda su vida. Si el hijo falleciere antes de transcurrir cuatro años desde que alcanzare mayoría de edad o recobrare capacidad suficiente a tales efectos, o durante el año siguiente al descubrimiento de las pruebas en que se funde la demanda, su acción corresponderá a sus herederos por el tiempo que faltare para completar dichos plazos. 2. Igualmente podrán ejercitar la presente acción de filiación los progenitores en el plazo de un año contado desde que hubieran tenido conocimiento de los hechos en que hayan de basar su reclamación. Esta acción no será transmisible a los herederos quienes solo podrán continuar la acción que el progenitor hubiere iniciado en vida».

${ }^{16}$ El artículo 136 del Código Civil dispone que «1. El marido podrá ejercitar la acción de impugnación de la paternidad en el plazo de un año contado desde la inscripción de la filiación en el Registro Civil. Sin embargo, el plazo no correrá mientras el marido ignore el nacimiento. Fallecido el marido sin conocer el nacimiento, el año se contará desde que lo conozca el heredero. 2. Si el marido, pese a conocer el hecho del nacimiento de quien ha sido inscrito como hijo suyo, desconociera su falta de paternidad biológica, el cómputo del plazo de un año comenzará a contar desde que tuviera tal conocimiento. 3. Si el marido falleciere antes de transcurrir el plazo señalado en los párrafos anteriores, la acción corresponderá a cada heredero por el tiempo que faltare para completar dicho plazo»; el artículo 137 Cc. señala que «l. La paternidad podrá ser impugnada por el hijo durante el año siguiente a la inscripción de la filiación. Si fuere menor o tuviere la capacidad modificada judicialmente, el plazo contará desde que alcance la mayoría de edad o recobrare capacidad suficiente a tales efectos. El ejercicio de la acción, en interés del hijo que sea menor o tuviere la capacidad modificada judicialmente, corresponderá, asimismo, durante el año siguiente a la inscripción de la filiación, a la madre que ostente la patria potestad, a su representante legal o al Ministerio Fiscal. 2. Si el hijo, pese a haber transcurrido más de un año desde la inscripción en el registro, desde su mayoría de edad o desde la recuperación de la capacidad suficiente a tales efectos, desconociera la falta de paternidad biológica de quien aparece inscrito como su progenitor, el cómputo del plazo de un año comenzará a contar desde que tuviera tal conocimiento. 3. Cuando el hijo falleciere antes de transcurrir los plazos establecidos en los párrafos anteriores, su acción corresponderá a sus herederos por el tiempo que faltare para completar dichos plazos. 4. Si falta en las relaciones familiares la posesión de estado de filiación matrimonial, la demanda podrá ser interpuesta en cualquier tiempo por el hijo o sus herederos»; y, por su parte, el artículo 139 Cc. prevé que «La mujer podrá ejercitar la acción de impugnación de su maternidad justificando la suposición del parto o no ser cierta la identidad del hijo».

${ }^{17}$ El artículo 140.1 Cc. señala que «Cuando falte en las relaciones familiares la posesión de estado, la filiación paterna o materna no matrimonial podrá ser impugnada por aquellos a quienes perjudique».

${ }^{18}$ El artículo 140.2 Cc. prevé que «Cuando exista posesión de estado, la acción de impugnación corresponderá a quien aparece como hijo o progenitor y a quienes por la filiación puedan resultar 
A nosotros nos interesa especialmente el artículo $133 \mathrm{Cc}$., y, en concreto, su segundo párrafo, que, tras la reforma operada a través de la Ley 26/2015, legitima al progenitor para reclamar la filiación no matrimonial cuando no existe posesión de estado, al disponer que «podrán ejercitar la presente acción de filiación los progenitores en el plazo de un año contado desde que hubieran tenido conocimiento de los hechos en que hayan de basar su reclamación». Como en seguida veremos, la reforma de dicho precepto estuvo marcada por la jurisprudencia tanto del Tribunal Supremo como del Tribunal Constitucional, que declaró la inconstitucionalidad del artículo 133 Cc. en su redacción anterior.

Por último, conviene hacer una breve referencia a la Ley de Enjuiciamiento Civil, que ha derogado expresamente los artículos 127-130 del Código Civil —que se entienden sustituidos por los arts. 748, 755 y 764 a 768 de la misma- y cuyo artículo 767.1 dispone que «En ningún caso se admitirá la demanda sobre determinación o impugnación de la filiación si con ella no se presenta un principio de prueba de los hechos en que se funde» ${ }^{19}$.

\section{IV) Jurisprudencia del Tribunal Supremo}

Ya antes de las Sentencias 273/05 y 52/06 del Tribunal Constitucional (que analizaré con detenimiento en el correspondiente apartado), el TS venía reconociendo la legitimación activa del supuesto progenitor para ejercitar la acción de reclamación de la filiación.

afectados en su calidad de herederos forzosos. La acción caducará pasados cuatro años desde que el hijo, una vez inscrita la filiación, goce de la posesión de estado correspondiente».

${ }^{19}$ La exigencia de tal principio de prueba, que ya venía establecida en el artículo 127 del Código Civil hoy derogado por la Ley 1/2000 de Enjuiciamiento Civil — ha sido interpretada por el Tribunal Supremo en el sentido de que no es necesario que aquél tenga que plasmarse en determinado documento acompañatorio de la demanda sino que basta con que en la misma conste la oferta de practicar determinadas pruebas en el momento adecuado. Así, entre otras muchas, en las Sentencias de 3 de diciembre de 1991 o 28 de diciembre de 2001. 
Entre otras ${ }^{20}$, en la Sentencia n. ${ }^{\circ} 726$ de 8 de julio de 2004, declaraba ser doctrina jurisprudencial consolidada reconocer la legitimación al padre para reclamar la filiación no matrimonial aunque no exista posesión de estado, superando así la literalidad del artículo 133, párrafo primero del CC, con el siguiente argumento: "es doctrina jurisprudencial reiterada (sentencias de 24 de junio de 1996; 30 de marzo y 19 de mayo de 1998; 20 de junio de 2000 y 22 de marzo de 2002) la que reconoce la legitimación del padre en los casos de filiación no matrimonial, aunque no exista posesión de estado superando la literalidad del artículo 133 del Código Civil y afirmando que ya que el artículo 134 del mismo cuerpo legal legitima en todo caso al progenitor para impugnar la filiación contradictoria, ha de entenderse que también le está habilitando para el ejercicio de la acción de reclamación de filiación extramatrimonial, pues ni puede prescindirse de la verdad biológica, ni debe echarse en olvido el interés justificado de los hijos en saber y conocer quién es su padre”.

Aunque la intención del Tribunal Supremo era buena, creo que estaba llevando a cabo una interpretación algo discutible, por cuanto podía resultar contraria a la propia letra de la ley. De hecho, hubo varias voces en la doctrina que consideraron que los pronunciamientos del Tribunal Supremo en esta cuestión contrariaban claramente la interpretación literal y sistemática de los arts. 133 y 134 CC y representaban una injustificada intromisión de los Tribunales en la creación de Derecho ${ }^{21}$.

\section{V) La declaración de inconstitucinalidad del art. 133.1 Cc.}

${ }^{20}$ El Tribunal Supremo ya se había pronunciado en este sentido anteriormente en sus sentencias: STS de 21 de abril de 1988 ( RJ 1988, 3268), 10 de marzo ( RJ 1988, 1815) y 3 de junio de 1988 ( RJ 1988, 4736) , 19 de enero (RJ 1990, 15), 23 de febrero de 1990 (RJ 1990, 2755) y 8 de julio de 1991 ( RJ 1991, 5569).

${ }^{21}$ Vid. GARcía CANTERO, Gabriel, "Legitimación activa para reclamar la filiación no matrimonial, sin posesión de estado. Crítica a una dirección jurisprudencial de la Sala $1^{a}$ del Tribunal Supremo”, Revista Jurídica del Notariado, No 36, 2009; GASCÓN INCHAUSTI, Fernando, "Cuestiones procesales en el ejercicio de las acciones de filiación", Tribunales de Justicia, M $^{\circ}$ 12, 2000; GARCÍA AMADO, Juan Antonio, “¿Interpretación judicial con propósito de enmienda (del legislador)? Acerca de la jurisprudencia sobre el artículo 133 del Código Civil”, Diario La Ley, tomo 5, 2001; y BARBER CÁRCAMO, Roncesvalles y CASAL HERNÁNDEZ, Jesús M., "Nuevas coordenadas para el derecho de filiación en Europa", Actualidad Civil, nº 6, 2009. 
a) Análisis de las sentencias del Tribunal Constitucional $n^{o} 273 / 2005$, de 27 de octubre y $n^{\circ}$ 52/2006, de 16 de febrero

En este apartado analizaré las Sentencias del Tribunal Constitucional nº 273/2005, de 27 de octubre de 2005 y n $^{\circ}$ 52/2006, de 16 de febrero de 2006, que incidieron notablemente en la materia que nos ocupa, al declarar la inconstitucionalidad del punto primero de la redacción anterior del artículo $133 \mathrm{Cc}$, en la medida en ampliar la legitimación activa para ejercitar la acción de reclamación de la filiación no matrimonial al progenitor cuando falte la respectiva posesión de Estado. Me centraré con mayor detalle en el análisis de la Sentencia n ${ }^{\circ}$ 273/2005, pues, en líneas generales, la Sentencia $n^{\circ} 52 / 2006$ se limita a reproducir y confirmar la doctrina sentada por la primera.

Con fecha 16 de abril de 1998, la Sección Primera de la Audiencia Provincial de Ciudad Real presentó escrito por el cual se presentaba cuestión de inconstitucionalidad referida al art. 133, párrafo primero, del Código civil, por vulneración de los arts. 14, 24.1 y 39.1 y 2 CE.

Los antecedentes que llevaron a la Audiencia Provincial de Ciudad Real a plantear la citada cuestión de inconstitucionalidad son en síntesis los siguientes: D. Arnes presentó ante el Juzgado de Primera Instancia de Tomelloso acción de reclamación, reconocimiento e inscripción de la filiación paterna no matrimonial del menor Sebastián, fruto, según afirmaba el actor, de la relación habida entre él y Da María del Pilar. Al respecto, ejercitó acción de reclamación del derecho a la patria potestad y establecimiento del régimen de visitas sobre dicho menor. Previamente, dentro del plazo para formalizar la inscripción de nacimiento del citado menor. D. Arnes inició expediente gubernativo de reconocimiento e inscripción de filiación paterna ante el Juez encargado del Registro Civil de Tomelloso, que se resolvió mediante providencia que declaró no haber lugar a lo interesado, por no ser el procedimiento seguido conforme con el artículo 120 del Código Civil, debiendo ejercerse la acción de reconocimiento de paternidad a través del procedimiento declarativo correspondiente. En la misma línea, el actor instó ante Notario Acta de manifestaciones en la que se reconoce como padre del menor. Recibidos los autos a prueba, ambas partes propusieron pruebas documentales y testificales, y el actor, 
además, la realización de las pertinentes pruebas biológicas, conducentes a la determinación de la paternidad reclamada. Declaradas pertinentes las pruebas propuestas —en concreto las pruebas biológicas, hematológicas y de ADN-, la representación de la demandada comunicó al Juzgado que no aceptaba la toma de muestras para las pruebas de paternidad solicitadas. La Sentencia del Juzgado de Primera Instancia núm. 1 de Tomelloso declaró a favor del actor la paternidad reclamada y los derechos y obligaciones derivados de la misma, ordenándose al Registro Civil de Tomelloso que se procediera a la inscripción marginal de la paternidad declarada. Da María del Pilar, por su parte, interpuso recurso de apelación contra la citada resolución ante la Audiencia Provincial de Ciudad Real. Finalmente, dicho Tribunal interpuso cuestión de inconstitucionalidad ante el Alto Tribunal en relación a la posible vulneración de los artículos $14,24.1$ y 39.1 y 2 CE por parte de punto primero del art. 133 Cc.

A continuación analizaré los pronunciamientos del Tribunal Constitucional en cada una de las vulneraciones de preceptos constitucionales que se plantean:

En primer término, se consideraba que el artículo $133.1 \mathrm{Cc}$ colisionaba con el derecho a la igualdad ante la ley previsto en el artículo $14 \mathrm{CE}$ en un doble sentido: por una parte, porque consagraba una diferenciación de trato, en los supuestos de falta de posesión de estado, según el origen matrimonial o no de la filiación; y por otra parte, por la desigualdad que producía entre los progenitores, al favorecer al que primero determina la filiación por medio del reconocimiento. Por lo que se refiere al primer aspecto, el Tribunal Constitucional recuerda que sólo las diferencias normativas no basadas en situaciones objetivas o razonablemente distintas, o que establezcan consecuencias jurídicas desproporcionadas con la finalidad pretendida, merecen un reproche desde el principio de igualdad ante la ley recogido en el artículo14 CE, en lo que entiende no incurre el precepto enjuiciado, recogiendo al respecto la doctrina del Tribunal Europeo de Derechos Humanos en relación con el artículo 14 del Convenio Europeo de Derechos Humanos (RCL 1999, 1190, 1572): el principio de igualdad no implica en todos los casos un tratamiento legal igual con abstracción de cualquier elemento diferenciador de relevancia jurídica, de manera que no toda desigualdad de trato normativo respecto a la 
regulación de una determinada materia supone una infracción del mandato contenido en el artículo 14 CE.

Por todo ello el Alto Tribunal consideró que el artículo 133.1 Cc no vulneraba el principio de igualdad que prevé el artículo 14 de nuestra Carta Magna.

En cuanto a la posible colisión del citado precepto con el artículo 24.1 de la Constitución, que prevé el derecho a la tutela judicial efectiva, el Tribunal señaló que resulta claro que no podemos partir de una consideración abstracta del derecho a la tutela judicial efectiva sin indefensión, sino que, por la naturaleza instrumental de éste es preciso tener en cuenta los derechos o intereses en juego que determinan los bienes constitucionales protegidos por el precepto impugnado. Esto obliga a conectar el examen con el de los principios rectores recogidos en el artículo 39 CE. Al respecto el Tribunal Constitucional manifestó que, aunque no pueda hablarse de la existencia de un derecho de los progenitores sobre los hijos como correlato de la existencia de los deberes que les impone el artículo 39.3 CE, la investigación de la paternidad no puede quedar reducida a un derecho del hijo, con exclusión de toda iniciativa por parte de los progenitores, pues también a éstos alcanza un interés en el conocimiento de la verdad biológica.

En el mismo sentido, el Tribunal Constitucional consideró que en la articulación del régimen de la acción de reclamación de la filiación extramatrimonial, el legislador dio mayor relevancia al interés del hijo y al principio de seguridad jurídica en el estado civil de las personas, pero desatendió por completo el interés del progenitor en obtener la declaración de su paternidad. Al respeto, señaló que el sacrificio que se impone no resulta constitucionalmente justificado desde el momento en que, aparte de que podría haber sido sustituido por otras limitaciones — como la imposición de límites temporales a la posibilidad de ejercicio de la acción-, el sistema articulado por nuestro ordenamiento no permite, en ningún caso, el planteamiento y la obligada sustanciación de acciones que resulten absolutamente infundadas, desde el momento en que, a tal efecto, se prevé que "en ningún caso se admitirá la demanda si con ella no se presenta un principio de prueba de los hechos en que se funda" — art. 767.1 de la Ley de Enjuiciamiento Civil—.

Por todo ello, el Tribunal concluyó que la privación al progenitor de la posibilidad de reclamar una filiación no matrimonial en los casos de falta de posesión de estado no 
resultaba compatible con el mandato del artículo $39.2 \mathrm{CE}$ de hacer posible la investigación de la paternidad ni, por ello, con el derecho a la tutela judicial efectiva art. 24.1 CE- .

A continuación me referiré brevemente a la Sentencia del Tribunal Constitucional $n^{\circ} 52 / 2006$ de 16 de febrero de 2006, que en la misma línea del pronunciamiento anterior, declara inconstitucional el artículo 133.1 del Código Civil. En este caso la cuestión de inconstitucionalidad es planteada nuevamente por la Audiencia Provincial de Ciudad Real el 19 de mayo de 2004. Igual que en la anterior cuestión de inconstitucionalidad planteada, se alega la vulneración de los artículos 14, 24.1 y 39 CE.

En sus fundamentos de derecho, el Tribunal Constitucional se remitió a los razonamientos contenidos en su Sentencia 273/2005, que, a su juicio, daban cumplida respuesta a cada una de las perspectivas desde las que el órgano promotor de la misma ponía en tela de juicio la constitucionalidad artículo 133 Cc. También lo hizo finalmente en su conclusión de que la privación al progenitor de la posibilidad de reclamar una filiación no matrimonial en los casos de falta de posesión de estado no viola el principio de igualdad previsto en el artículo 14 de nuestra Constitución, pero si contraviene el mandato del artículo. 39.2 de hacer posible la investigación de la paternidad, así como el derecho a la tutela judicial efectiva, previsto en el artículo 24.1 CE.

A mi modo de ver, los pronunciamientos del Tribunal Constitucional resultaron acertados. Incluso creo que se quedó corto en sus apreciaciones al no considerar la vulneración del principio de igualdad previsto en el artículo 14 de la Constitución, pues no parece que nos encontráramos ante un supuesto en el que la normativa diera diferente trato a situaciones diferentes, sino que llevaba a cabo una diferenciación injustificada en los derechos previstos para los padres en función de su estado civil de casado o no casado, así como en el hecho de que existiera o no posesión de estado, lo que, por otro lado, en muchos casos podía deberse que el progenitor ni siquiera hubiera tenido oportunidad de disfrutar de la citada posesión de estado.

No obstante lo anterior, lo cierto es que las Sentencias incluían dos votos particulares que se oponían a la declaración de inconstitucionalidad del artículo 133 del 
Código Civil por considerar que los intereses del progenitor ya quedaban suficientemente amparados por la posibilidad de acudir a la vía del reconocimiento. Sin embargo, a mi modo de ver, el mencionado argumento resulta bastante cuestionable, toda vez que hay algunos supuestos en nuestro Código Civil en los que la vía del reconocimiento resulta vedada al progenitor, sin posibilidad de recurso ${ }^{22}$. Es lo que ocurre por ejemplo en el caso del reconocimiento del hijo mayor de edad, que requiere en todo caso el consentimiento del propio hijo - art. $123 \mathrm{CC}$ - o en el del hijo ya fallecido, que exige el consentimiento de sus descendientes — art. $126 \mathrm{CC}$ -

\section{b) Efectos de los pronunciamientos constitucionales}

Como hemos visto en el análisis jurisprudencial de los pronunciamientos del Tribunal Constitucional que ha precedido a este apartado, una vez expuesto el razonamiento que sirve de fundamento para la declaración de inconstitucionalidad del artículo 133.1 del Código Civil, el Tribunal optó por no decretar la nulidad del mismo, con el siguiente argumento: "En el presente caso es evidente que no procede declarar la nulidad de la regla legal que, en ausencia de posesión de estado, otorga al hijo la legitimación para reclamar la filiación no matrimonial durante toda su vida, pues tal pronunciamiento, además de no reparar la inconstitucionalidad apreciada, dañaría, sin razón alguna, a quienes ostentan, en virtud del art. 133 Cc., y en forma plenamente conforme con los mandatos del art. $39 \mathrm{CE}$, una acción que no merece tacha alguna de inconstitucionalidad. Así pues, la declaración de nulidad de este precepto, consecuente a la declaración de inconstitucionalidad, generaría un vacío normativo, sin duda no deseable".

Por tanto, el Tribunal no consideró adecuado en aras del principio de seguridad jurídica declarar la nulidad del artículo 133 Cc. A mi modo de ver, la solución que alcanzó el Tribunal Constitucional de declarar la inconstitucionalidad del artículo $133.1 \mathrm{Cc}$ sin dictaminar su nulidad resulta muy acertada, pues de lo contrario se habría privado del ejercicio de las acciones de reclamación de la filiación a quién hasta el momento sí se lo permitía la redacción del precepto, es decir, se habrían vulnerado los legítimos intereses

${ }^{22}$ Vid. en este mismo sentido: BARBER CÁRCAMO, Roncesvalles y CASAL HERNÁNDEZ, Jesús M., "Nuevas coordenadas...", cit. 
de los hijos no matrimoniales. Además, se hubiera producido un vacío normativo que habría generado inseguridad jurídica.

En realidad, creo que lo que hizo el Tribunal Constitucional fue dar un toque de atención al legislador y realizar un llamamiento al mismo para que, mediante los cauces legales pertinentes, procediera a la apertura del correspondiente procedimiento legislativo tendente a la modificación del precepto mencionado.

Las principales críticas que los autores civilistas vertieron contra los pronunciamientos jurisprudenciales que han sido objeto de análisis se basaron principalmente en el hecho de que la acción para reclamar la filiación no matrimonial cuando no existe posesión de estado podría convertirse en una especie de acción pública, la cual podría ejercitarse por cualquier persona independientemente de que existiese o no algún tipo de indicio de que la filiación biológica coincide con la filiación jurídica que se reclama ${ }^{23}$. No obstante, considero que dicho problema queda superado por la previsiones del artículo 767.1 de la Ley de Enjuiciamiento Civil para poder presentar una demanda sobre determinación o impugnación de la filiación, exigiendo la existencia de principio de prueba de los hechos en que se funda ${ }^{24}$. La prueba exigida para presentar dicha demanda dependerá de la circunstancias concretas de cada caso $^{25}$.

\footnotetext{
${ }^{23}$ Vid. BALLARÍn HERNÁNDEZ, Rafael, "Sobre la legitimación del reconocedor paterno, por vía exenta de cumplimientos, para ejercitar las acciones de filiación, si se deniega la confirmación de la inscripción de reconocimiento suspendida: art.124.II CC, incisos segundo y tercero", en: Estudios jurídicos en homenaje al profesor Luis Díez-Picazo —coord. CABANILlas SÁnCHEZ, Antonio-, Vol. 3, 2002.

${ }^{24}$ Vid. en este mismo sentido: LlAMAS POMBO, Eugenio y TORAL LARA, Estrella, "Estudio particular de las principales novedades en las concretas acciones de filiación", en: Nuevos conflictos en el Derecho de Familia, La Ley, 2009.

${ }^{25}$ Como señala RUBio TORRANO, en el caso de personas conocidas o famosas, no debería ser suficiente con que alguien presente una demanda diciendo que una determinada persona es su padre o su hijo y se limite a pedir la prueba de ADN, sino que lo lógico es que se exija la presentación de otros indicios como condición para admitir la demanda. Y en el caso de menores que ya tienen un padre legal, el hecho de admitir sin ningún indicio previo la demanda de cualquier hombre que pretende su paternidad puede vulnerar sus derechos, los de su madre y los del padre legal -RUBIO TORRANO, Enrique, "Inconstitucionalidad del Art. 133, párrafo 1², del Código Civil", Aranzadi Civil: revista quincenal, № 3 , 2005-.
} 


\section{VI) La reforma operada a través de la Ley $26 / 2015$}

Como he anticipado, el artículo 2.3 de la Ley 26/2015, de 28 de julio, modificó el artículo 133 Cc., en el que introdujo un párrafo segundo que pasó a disponer que «Igualmente podrán ejercitar la presente acción de filiación los progenitores en el plazo de un año contado desde que hubieran tenido conocimiento de los hechos en que hayan de basar su reclamación». Para llevar a cabo dicha reforma, el legislador tuvo en cuenta la jurisprudencia dimanante del Tribunal Constitucional, como expresamente reconoció en su Exposición de Motivos $^{26}$.

Al respecto, cabe destacar el hecho de que se haya plasmado por fin en un texto legal la posibilidad de que el progenitor respecto al que no existe posesión de estado pueda ejercitar la acción de reclamación de la filiación no matrimonial.

De acuerdo a la nueva redacción del artículo 133.2 Cc., dicha acción podrá ejercitarse en el plazo de un año desde que se hubiera tenido conocimiento de los hechos en los que se basa la reclamación. A mi modo de ver, resulta acertado someter la nueva legitimación activa del progenitor a un límite temporal que garantice el respeto al principio de seguridad jurídica, un plazo que, siguiendo a BARBER CÁRCAMO, cabe entender que el plazo debe ser considerado de caducidad, no admitiendo suspensión ni interrupción ${ }^{27}$. No obstante lo anterior, tal y como ha puesto de manifiesto MARTíNEZ DE AGUIRRE ALDAZ, hubiera resultado preferible optar por el criterio de la cognoscibilidad en vez del criterio del conocimiento para fijar el dies a $q u o^{28}$, es decir, el plazo debería

\footnotetext{
26 «Por otra parte, se modifican las normas sobre acciones de filiación. La regulación que se propone responde a que el primer párrafo del artículo 133 ha sido declarado inconstitucional, en cuanto impide al progenitor no matrimonial la reclamación de la filiación en los casos de inexistencia de posesión de estado (sentencias del Tribunal Constitucional número 273/2005, de 27 de octubre de 2005, y número 52/2006, de 16 de febrero)».
}

27 Vid. BARBER CÁRCAMO, Roncesvalles, "La legitimación del progenitor para reclamar su paternidad", Aranzadi Civil: revista quincenal, No 2, 2006. Vid. también en este mismo sentido: UrEÑA CARAZO, Belén, "Acciones de filiación e interés del menor: un análisis tras la Ley 26/2015, de 28 de julio, de modificación del sistema de protección a la infancia y a la adolescencia”, La Ley Derecho de familia, № 9, 2016.

${ }^{28}$ Vid. MARTínez de AgUiRre AldaZ, Carlos, "La filiación", cit., p. 363. 
LA LEGITIMACIÓN DEL SUPUESTO PROGENITOR PARA EJERCITAR LA ACCIÓN DE RECLAMACIÓN DE LA FILIACIÓN NO MATRIMONIAL SIN POSESIÓN DE ESTADO

comenzar a contar desde el momento en el que el progenitor "pudiera conocer" su presunta paternidad, y no del momento en el que efectivamente la conozca.

\section{VII) Bibliografía}

Alzueta Goyeneche, Loreto. "Paternidad legal y biológica: debe prevalecer la segunda", Revista Aranzadi Doctrinal, № 7, 2010.

BALLARÍn HERnÁNDEZ, Rafael, " Sobre la legitimación del reconocedor paterno, por vía exenta de cumplimientos, para ejercitar las acciones de filiación, si se deniega la confirmación de la inscripción de reconocimiento suspendida: art.124.II CC, incisos segundo y tercero", en: Estudios jurídicos en homenaje al profesor Luis Díez-Picazo — coord. CABAniLlas SÁnCHEZ, Antonio-, Vol. 3, 2002, pp. 1099-1119.

BARBER CÁRCAMO, Roncesvalles, "Hacia la pacificación de la acción de impugnación de la filiación marital", Aranzadi Civil: revista quincenal, № 3, 2005, pp. 2253-2282.

BARBER CÁRCAMO, Roncesvalles, "La legitimación del progenitor para reclamar su paternidad", Aranzadi Civil: revista quincenal, N 2, 2006, pp. 2149-2192.

BARBER CÁrCAmo, Roncesvalles y CASAl HERnÁNDEZ, Jesús M., "Nuevas coordenadas para el derecho de filiación en Europa", Actualidad Civil, nº 6, 2009.

BERCOVITZ RODRÍGUEZ-CANO, Rodrigo “A vueltas con la prueba biológica de paternidad”, Aranzadi Civil: revista quincenal, № 2, 2007, pp. 2323-2324.

CARRASCo PERERA, Ángel "Evans o la engorrosa investigación de la paternidad", Actualidad Jurídica Aranzadi, № 727, 2007.

GARCÍA AMADO, Juan Antonio, “¿Interpretación judicial con propósito de enmienda (del legislador)? Acerca de la jurisprudencia sobre el artículo 133 del Código Civil”, Diario La Ley, tomo 5, 2001. 
GARCÍA CANTERO, Gabriel, "Legitimación activa para reclamar la filiación no matrimonial, sin posesión de estado. Crítica a una dirección jurisprudencial de la Sala $1^{\text {a }}$ del Tribunal Supremo”, Revista Jurídica del Notariado, № 36, 2009

GARcía Vicente, José Ramón. "Los principios del Derecho de las acciones de filiación", Aranzadi Civil: revista quincenal, № 1, 2004, pp. 2151-2166.

GASCÓN INCHAUSTI, Fernando, “Cuestiones procesales en el ejercicio de las acciones de filiación”, Tribunales de Justicia, $\mathrm{M}^{\mathrm{o}}$ 12, 2000.

Llamas POMBO, Eugenio y TORAL LARA, Estrella, "Estudio particular de las principales novedades en las concretas acciones de filiación”, en: Nuevos conflictos en el Derecho de Familia, La Ley, 2009.

MARTíneZ de AguiRre Aldaz, Carlos, "La filiación, entre biología y derecho", Prudentia iuris, № 76, 2013, pp. 79-106.

Martínez de Aguirre Aldaz, Carlos, "La filiación", en: Curso de Derecho Civil (IV): Derecho de familia — coord. MARTíneZ DE AGuirRe AldAZ, Carlos-, Edisofer, 2016, $5^{\text {a }}$ ed., pp. 321-354.

PULIDO QUECEDO, Manuel, "Sobre el valor probatorio de la negativa a someterse a la prueba biológica de la paternidad", Repertorio Aranzadi del Tribunal Constitucional, $\mathrm{N}^{\mathrm{o}}$ 3, 2005, pp. 9-12.

Pulido QueCEDO, Manuel, "De nuevo sobre las pruebas de investigación de paternidad (Nota sobre la STC 177/2007, de 23 de junio, RTC 2007, 177)", Repertorio Aranzadi del Tribunal Constitucional, $\mathrm{N}^{\circ} 12,2007$, pp. 9-12.

RUBiO TORRANO, Enrique, "Filiación extramatrimonial y prueba biológica de paternidad", Aranzadi Civil: revista quincenal, No 1, 2005, pp. 2177-2178.

Rubio Torrano, Enrique, "Inconstitucionalidad del Art. 133, párrafo 1º, del Código Civil”, Aranzadi Civil: revista quincenal, № 3, 2005, pp. 2152-2154.

UREÑA CARAZO, Belén, “Acciones de filiación e interés del menor: un análisis tras la Ley 
LA LEGITIMACIÓN DEL SUPUESTO PROGENITOR PARA EJERCITAR LA ACCIÓN DE RECLAMACIÓN DE LA FILIACIÓN NO MATRIMONIAL SIN POSESIÓN DE ESTADO

26/2015, de 28 de julio, de modificación del sistema de protección a la infancia y a la adolescencia", La Ley Derecho de familia, № 9, 2016. 